\title{
MANAGING BUSINESS ENVIRONMENTS IN TIER 1 AND TIER 2 CITIES IN CHINA: IMPLICATIONS FOR TAX REVENUE AND TOTAL INVESTMENT
}

\author{
Erik Benrud*
}

\begin{abstract}
We demonstrate how the existence of Tier 1 and Tier 2 cities in China can lower direct competition between cities for foreign investment and increase the total investment in China. The Tier 1 cities provide a higher quality business environment in terms of law and contract enforcement and infrastructure, but foreign firms doing business in Tier 1 cities incur higher explicit costs from a higher tax rate. Foreign firms can choose to invest in and operate in Tier 2 cities that have lower tax rates, but there are greater risks to the foreign investors from the lower quality business environment. We demonstrate how a stable equilibrium can exist in this competition for foreign investment, where the managers of each city choose the tax rate and the quality of the business environment. In equilibrium, these choice variables are functions of exogenous factors such as the number of investors and their ability to deal with a less-than-perfect business environment. Comparative statics can predict how the choice variables will change in reaction to changes in the exogenous factors. Finally, we demonstrate how control by the central government of the tax rates and qualities in the different cities can increase total tax revenue from the foreign investment but would also cause a decline in foreign investment.
\end{abstract}

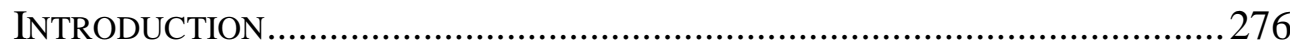

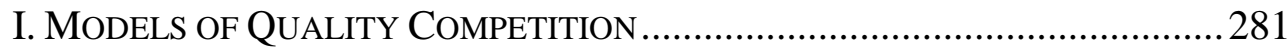

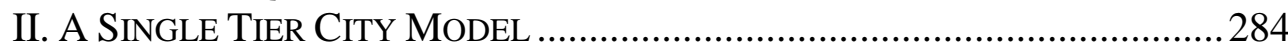

III. COMPETITION BETwEen TIER 1 AND TIER 2 CitieS ...............................28

IV. The EFFECT OF EXogenous SHIFTS IN THE TIER 1 AND TIER 2 City

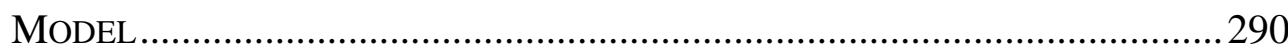

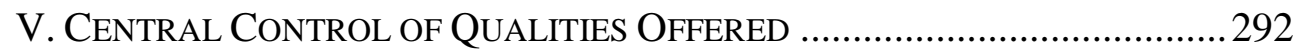

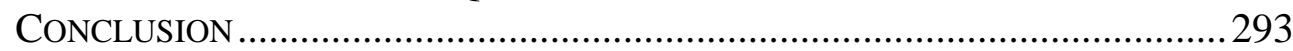

\section{INTRODUCTION}

Research into the nature of developing economies is crucial in helping policymakers understand and facilitate the growth of those economies. Within a given developing economy, there is likely to be a variety of different qualities of business environments among the various geographic regions in the country. This would give investors in that economy choices

${ }^{*}$ Peking University HSBC Business School, Shenzhen, China. Research fields: Alternative Investments, Derivatives, Competition in Financial Markets. 
with respect to where to make investments. There would be more developed areas with higher explicit costs, e.g., higher taxes, and less developed regions with lower explicit costs but higher implicit costs such as lower quality municipal services and a lower level of regulatory enforcement. The existence of different regions with different levels of development may actually be positive for both the investors and the developing economy because it offers investors choices and may increase the total investment and tax revenue for the developing economy. There may be welfare benefits for the developing economy if a strong central government like that in China can mandate the tax rates and quality levels.

China has diverse regions, and different levels of business environments coexist within the country. Many analysts and members of the business community classify the cities into tiers. Foreign investors can choose to do business in a Tier 1 city like Beijing, Shanghai or Guangzhou, with a higher quality business environment but also with a higher level of explicit costs in the form of taxes. Or, foreign investors can choose to do business in a lower tier city where the levels of explicit costs are lower but where there are higher implicit costs from the less-than-perfect business environments in those regions. What is the future of this multi-tiered system of business environments? Several results are possible. One result could be that the lower-tier cities make an effort to increase the quality of their business environments to a level equal to that of the Tier 1 cities. Another result is that the current situation could continue in a stable equilibrium where the tiers of cities remain distinct and adjust the qualities of their business environments in absolute terms and also in relative terms to each other in response to internal and external developments. The latter result could be more beneficial to the Chinese economy in that the lower tier cities avoid direct competition with the Tier 1 cities. In this case, the Chinese economy could offer foreign investors more choices, which could increase the total foreign investment in China and may lower tax revenue.

"There's energy, a dynamism, in China. And yet China is a country, still, of great contrast," according to John Locke, the current US Ambassador to China (NPR 2012) ${ }^{1}$. An article in the China Business Review observes that "the China market is highly fragmented with significant differences between cities and regions. They (foreign businesses) must also choose an appropriate location with a market environment most suitable to their industry and objectives." Challenges include "selective enforcement of World Trade Organization rules, vulnerable intellectual property rights,

\footnotetext{
${ }^{1}$ NPR: National Public Radio, Locke: China Is a Country of Great Contrasts (January 18, 2012). http://www.npr.org/2012/01/18/145384412/ambassador-locke-shares-his-impressions-of-china.
} 
governmental restrictions on foreign ownership, local content requirements, and competition from established domestic enterprises." ${ }^{2}$ One reason for the contrasts is that, despite great progress in recent decades, in many ways China's economy is still a developing economy. In some ways, however, China's has advanced above other developing nations, and different regions are at different stages of development.

The Chinese central government authorities play an important role in determining the business environment. In its pursuit of development, the Chinese government authorities have created many contrasting arrangements and choices for consumers, workers and investors. Entities and arrangements of different types coexist in an interesting balance. One example of this is the coexistence of state-owned and private enterprises. The pension system is another example. As the central Chinese government has moved away from its cradle-to-grave "Iron Rice Bowl Policy", it has developed a multi-pillar system for providing pensions (CFA 2009) ${ }^{3}$.

A multi-tier system has also emerged with respect to the development of the various regions or cities. Henceforth, we use the term "city" instead of "region" because most analyses on this topic use the monikers Tier 1 cities, Tier 2 cities, Tier 3 cities, etc.. ${ }^{4}$ The Chinese central government does not classify the Chinese cities into tiers, so an official set of definitions that distinguish the tiers does not exist. In the world business community, most would agree that Beijing, Shanghai and Guangzhou are the Tier 1 cities. The Chinese central government opened these three cities up for competitive economic development first, and they are also the most populous, but others may qualify. The consulting group Nexus-Pacific also includes Shenzhen and Tianjin in Tier 1 and proposes a list of 30 Tier 2 cities: Changchun, Changsha, Chengdu, Dalian, Fuzhou, Guiyang, Haikou, Hangzhou, Harbin, Hefei, Hohhot, Jinan, Kunming, Lanzhou, Lhasa, Nanchang, Nanjing, Nanning, Ningbo, Qingdao, Sanya, Shantou, Shenyang, Suzhou, Taiyuan,

\footnotetext{
${ }^{2}$ Craig, Richard and Jacqueline Qiang, China's Emerging Tier 2 Cities: Opportunities for US Companies (November 1, 2010). Available at http://www.chinabusinessreview.com/chinas-emergingtier-2-cities-opportunities-for-us-companies/.

${ }^{3}$ CFA Institute, Pension Fund Reforms in China: An Opportunity to Promote Codes of Conduct and Standards of Best Practice. Asia Pacific Office of the CFA Institute Centre for Financial Market Integrity (2009). Available at http://www.cfainstitute.org/ethics/Documents/Codes\%20Documents/china_pension_.

${ }^{4}$ The prevalence of the perception of distinct tiers is seen in trade publications where articles have titles such as "China's Emerging Tier 2 Cities: Opportunities for US Companies", available at http://www.chinabusinessreview.com/chinas-emerging-tier-2-cities-opportunities-for-us-companies/ and "China's Best Kept Secrets: Mianyang And Other Tier 3 Cities", available at http://www.forbes.com/sites/jackperkowski/2012/05/11/chinas-best-kept-secrets-mianyang-and-othertier-3-cities/print/.
} 
Urumqi, Wuhan, Wuxi, and Xiamen. The Tier 2 cities have twice as many households and twice the income as the Tier 1 cities. ${ }^{5}$

There are risks associated with the lower-tier cities. The following is from a report issued by the International Bar Association, and it is indicative of the type of advice that public agencies and private consulting firms publish for the benefit of those who plan to do business in China.

There's no denying that there are still plenty of opportunities to make money in China. But it's also clear that China's investment landscape is changing.

Although they still have further to go, China's first-tier cities (Beijing, Shanghai, Guangzhou and Shenzhen) are now well-developed bastions of capitalism - albeit with a very strong socialist flavour. For those cities, to quote Churchill, "it is, perhaps, the end of the beginning". Foreign money is increasingly flowing further inland as smart investors follow the lead of the Chinese Government's Go West programme....

...Outside Beijing and Shanghai, there is a complex network of provincial and city-level regulations overlaid on the national law. These are often quite opaque, with little information available in English. A lack of strict filing requirements means it is difficult to get up-to-date information on private companies. It is also more common to encounter unscrupulous auditors and local officials who will turn a blind eye. ${ }^{6}$ (Taylor 2011)

The message is that there are opportunities in lower-tier cities, but there are also more implicit costs from the additional risks of the business environment in those cities.

In an effort to increase foreign investment, the local city managers in the lower tier cities might consider managing the business environment to attract a certain portion of the potential. Our analysis suggests that it may not be optimal to attempt to improve a lower tier city's quality to meet the quality level in the Tier 1 cities. It may be more beneficial for the different tiers to offer varying choices of environments to potential foreign investors. Those foreign investors with the appropriate levels of expertise and risk tolerance with respect to lower quality business environments can choose to do business in the Tier 2 and Tier 3 cities and benefit from the lower tax rates and other costs. We propose that the cities may deliberately choose to offer distinct business environments, i.e., engage in product differentiation, to accommodate the different tastes and abilities of foreign investors.

This paper introduces a model that describes a competition between the

\footnotetext{
${ }^{5}$ Nexus Pacific, China City Tier System: How it Works and Why it's Useful (July 9, 2013). http://nexus-pacific.com/blog/2013/7/9/china-city-tier-system-how-it-works-and-why-its-useful. ${ }^{6}$ Phil Taylor, The Risks of the Middle Kingdom, IBA GLOBAL InSIGHT (2011). Available at http://www.ibanet.org/Article/Detail.aspx?ArticleUid=0f0af93c-dc6a-4fba-b62a-dc8a14416f1f.
} 
governments of a Tier 1 and Tier 2 city in terms of the business environment they offer to potential investors who are making a choice with respect to the location of their investment in China or other developing economies. The city managers of the two cities differentiate their cities by the quality of the business environment and the tax rates imposed on foreign investors. Each city government earns revenues determined by how many investors they attract and the tax rates they impose each city government incurs costs for providing a given level of business environment quality. Those looking to invest or do business in the Chinese cities have a profit function where the inputs are the expected pre-tax return, the local tax rate, and the implicit costs associated with the risks from a less-than-perfect business environment. The resulting model can help practitioners and researchers understand how various inputs such as the number of investors and their level of sophistication can determine the tax rates in each city tier, the proportion of investors who choose each tier, and the quality of the business environment in the different tiers.

Our model is an adaptation of a general model developed by Anderson, de Palma, and Thisse (1992), henceforth ADT. ${ }^{7}$ The ADT model is well established in the industrial organization literature, and it describes a duopoly market where the firms avoid direct competition by offering products with different qualities and prices. In recognition of the rapid development of China and the power the central government of China has in targeting the quality of the business environment, we build upon the ADT model by proposing that foreign investors have three choices. We assume that China's economy is in a stage of development between that of the developed economies and that of the lesser-developed economies. Foreign investors who wish to invest in a developing economy will choose either one of the lesser developed economies with a lower quality business environment or China. In the model, we assume China offers two distinct qualities of business environments, which are both higher than that of the lesser-developed economies.

The model shows how exogenous factors determine the percentage of foreign investors that choose Tier 1 or Tier 2 cities in China, or who choose to invest in a lesser developed economy outside of China. Those factors also determine the equilibrium quality levels of business environments, net revenues to the Tier 1 and Tier 2 city governments, and the tax rates. The exogenous parameters are the higher risk level associated with the lesser developed economies, the number of foreign investors, and the willingness

\footnotetext{
${ }^{7}$ Anderson, S., A. de Palma, \& J. Thisse, Discrete Choice Theory of Product Differentiation (Cambridge, MIT Press 1992).
} 
and ability of the foreign investors to deal with the risks associated with less-than-perfect business environments. The solutions allow researchers to analyze how changes in the exogenous parameters affect the decisions of the Tier 1 and Tier 2 cities in China. As the numbers of potential investors increase, for example, the business environments should improve. An increase in the expertise of foreign investors to deal with the risks, however, might lead to a decline in the quality of the environments. The findings can help in the analysis of the results of world trends such as the growth in the number of foreign investors choosing to make investments in developing economies and the increasing ability of those foreign investors to adapt to the business environments in China and other developing economies.

In addition to the traditional industrial organization analysis between competing firms, we investigate a possible outcome from the central government of China mandating the quality levels offered by the cities in the different tiers. The mandate would include a specified tax rate. In this scenario, the central government chooses quality levels and tax rates that will maximize tax revenue for China from foreign investors. Our analysis shows that net tax revenue will increase but there will be a decline in the foreign investment.

The review of the literature in the next section provides the sources of the theories and assumptions used in this model. After that section, we introduce the parameters assuming that there is only a Tier 1 city offering one business environment defined by its expected return, tax rate, and a measure of the risk associated with a less-than-perfect business environment. That city competes with lesser-developed economies outside of China that have a fixed, exogenous level of higher risk. After demonstrating the implications of that model, we expand the model to include a Tier 2 city whose government offers a lower quality environment with a lower tax rate. We employ comparative statics to demonstrate the implications of the model, which is followed by a summary and discussion.

\section{MODELS OF QUALITY COMPETITION}

Models analyzing the effects of quality competition are important because economic welfare is generally better when consumers and/or investors have a wider variety of products, services and investments from which to choose, see Mussa \& Rosen (1978) ${ }^{8}$ and Anderson et al., (1992) ${ }^{9}$.

\footnotetext{
${ }^{8}$ Mussa, M. and R. Sherwin, Monopoly and Product Quality, 18 Journal of EConOMic THeory 301317 (1978).

${ }^{9}$ Anderson, De Palma and Theisse (1992).
} 
Those agents that offer the products, services and investments can benefit from a being able to distinguish themselves and avoid direct competition. New entrants to an industry usually must find their own market niche, and that niche may be a quality that is different from the quality of existing products. Existing firms in the industry can benefit by allowing other firms to enter the industry with products that do not directly compete with the products already offered as opposed to the possibility of the new entrants directly competing with them. Previous researchers have verified how it is often too costly for monopolists offering a given quality of goods to prevent entrants with a different quality product from entering the market; see Dixit $(1980)^{10}$, Schwartz and Thompson (1986) ${ }^{11}$ and Schwartz and Baumann $(1987)^{12}$. This analysis can apply to both goods and services. In effect, the cities in China are offering municipal services, contract-enforcement, and other services to potential investors. Thus, the vertical differentiation models can apply to how the cities might position themselves relative to each other to attract a certain portion of the potential investors. This section summarizes the development of the literature that explores the dynamics and effects of this competitive process.

Over the years, a large literature has built upon early works such as Leland (1977) ${ }^{13}$ and Shaked and Sutton (1982) ${ }^{14}$ to show how quality differentiation relaxes price competition. The reason for such differentiation is to avoid the Bertrand (1883) ${ }^{15}$ outcome associated with firms that compete with the same quality product. Researchers created the moniker "Bertrand death" to describe a competitive situation where prices are falling and production costs are increasing from direct competition. In the resulting equilibrium, the firms have non-positive profits ${ }^{16}$. According to Sutton (1997) ${ }^{17}$, "loss-making strategies will be avoided" by firms; also, "if a profitable opportunity exists in the market, there is 'one smart agent' who will fill it." Rather than risking a competitive outcome where profits are non-positive, the entering firm can choose a quality that is different enough

\footnotetext{
${ }^{10}$ Dixit, A., The Role of Investment in Entry Deterrence, 90 Economic JouRnaL 95-106 (1980).

${ }^{11}$ Schwartz, M., and M. Baumann, Entry-deterrence Externalities and Relative Firm Size, 6 INTERNATIONAL JOURNAL OF INDUSTRIAL ORGANIZATION 181-197 (1988).

${ }^{12}$ Schwartz, M. and E. Thompson, Divisionalization and Entry Deterrence, 101 QUARTERLY JournaL OF ECONOMICS 307-321 (1986).

${ }^{13}$ Leland, H., Quality Choice and Competition, AMERICAN ECONOMIC REVIEw 67, 127-138 (1977).

${ }^{14}$ Shaked, A. and J. Sutton, Relaxing Price Competition through Product Differentiation, 49 REviEw of ECONOMIC STUDIES 3-14 (1982).

${ }^{15}$ Bertrand, J., Review of "Theorie Mathematique de la richesse sociale" and "Recherchesur les Principes Mathematiques de la Theorie des Richesses", Journal DES SAVANTS 499-508 (1883).

${ }^{16}$ Anderson, De Palma and Theisse (1992).

${ }^{17}$ Sutton, J., One Smart Agent, 28 RAND Journal of Economics 605-628 (1997).
} 
to allow it to not directly compete with the existing firm.

There is a lengthy literature on the entry of firms into industries where profit opportunities exist. Prescott and Visscher $(1977)^{18}$ and Hay $(1976)^{19}$ pioneered the modern sequential-entry models. Lane (1980) extended the model to allow for endogenous prices, and this development has characterized later models including the one in this paper. ${ }^{20}$ Subsequent works in this area include Shaked and Sutton $(1982)^{21}$, Harris $(1985)^{22}$, Eaton and Ware $(1987)^{23}$, Dewatripont (1987) ${ }^{24}$, Benoit and Krishna $(1987)^{25}$, Vives $(1988)^{26}$, Mclean and Riordan (1989) ${ }^{27}$, and Anderson et al. $(1992)^{28}$.

The model in our paper builds upon the model established in Anderson et al. $(1992)^{29}$, or ADT. The ADT model is a vertical differentiation model with a stable equilibrium. Furthermore, the consumer utility function of the ADT model easily adapts to the profit function of investors who pay a tax to do business in a Tier 1 or Tier 2 city and also incur additional costs from the less-than-perfect business environments in those cities.

As Sutton (1997) ${ }^{30}$ mentioned, there is usually not one "true model" to describe a given market. Several models may apply, and this paper lays a solid foundation for future work in this area by thoroughly investigating the results associated with the modification of an established spatial model in the industrial organizations literature. In our model, the second order conditions are satisfied, and the model yields a unique and stable equilibrium. Having successfully adapted one model from the industrial

\footnotetext{
${ }^{18}$ Prescott, E. and M. Visscher, Sequential Location among Firms with Foresight, 8 Bell Journal of ECONOMICS 378-393 (1997).

${ }^{19}$ Hay, D., Sequential Entry and Entry-deterring Strategies in Spatial Competition, 28 OXFORD ECONOMIC PAPERS 220-257 (1976).

${ }^{20}$ Lane, W., Product Differentiation in a Market with Sequential Entry, 11 BeLL JouRnAL OF ECONOMICS 237-260 (1980).

${ }^{21}$ Shaked and Sutton (1982).

${ }^{22}$ Harris, C., Existence and Characterization of Perfect Equilibrium in Games of Perfect Information, 53 ECONOMETRICA 613-616 (1985).

${ }^{23}$ Eaton, B., and R. Ware, Theory of Market Structure with Sequential Entry, 18 RAND JOURNAL OF ECONOMICS 1-16 (1987).

${ }^{24}$ Dewatripont, M., The Role of Indifference in Sequential Models of Spatial Competition, 23 ECONOMICS LETTERS 323-328 (1987).

${ }^{25}$ Benoit, J., and V. Krishna, Dynamic Duopoly: Prices and Quantities, 54 ReVIEw of EconOMIC STUDIES 23-35 (1987).

${ }^{26}$ Vives, X., Sequential Entry, Industry Structure and Welfare, 32 EuRopeAn ECONOMIC REvIEW 1671-1687 (1988).

${ }^{27}$ Mclean, R., and M. Riordan, Industry Structure with Sequential Technological Choice, 47 JOURNAL OF ECONOMIC THEORY 1-21 (1989).

${ }^{28}$ Anderson, De Palma and Theisse (1992).

${ }^{29}$ Anderson, De Palma and Theisse (1992).

${ }^{30}$ Sutton (1997).
} 
organizations literature to a developing economy with internal regions defined by the quality of the business environment, future research can explore the extent to which other models apply.

The next section summarizes the assumptions of the ADT model and modifies that model so that its inputs correspond to parameters in a developing economy where the city managers adjust the business environment to the tastes of potential foreign investors. That section lays the groundwork for the sections that describe an economy where a Tier 1 city and a Tier 2 city coexist and differentiate themselves by their respective business environments and the tax rates they impose on foreign investment. Those subsequent sections also demonstrate the impact of changes in exogenous parameters on the choice variables of the city managers in the Tier 1 and Tier 2 cities.

\section{A Single TIER City MODEL}

This section serves two purposes. First, it introduces the assumptions of the model as well as the parameters that describe the characteristics of the Tier 1 city and the foreign investors in the model. Second, this section derives the equilibrium where a Tier 1 city only competes with an exogenous investment opportunity with a lower-quality, exogenously determined business environment. The equilibrium is a standard result, but it sets the stage for examining the equilibrium when there is a Tier 1 and Tier 2 city.

To describe how the investors make their choices, we adapt the indirect utility function of consumers proposed by ADT. In the ADT model, indirect utility is a function of income, price, taste and quality, which are represented by $y, P_{i}, \theta$, and $q_{i}$, respectively:

$$
\mathrm{V}_{\mathrm{i}}(\theta)=\mathrm{y}-\mathrm{P}_{\mathrm{i}}+\theta \mathrm{q}_{\mathrm{i}}(\mathrm{i}=1 \ldots \mathrm{n})
$$

Each period, consumers purchase and consume a single unit of the product indexed $\mathrm{i}$. The price and quality of the product are $\mathrm{P}_{\mathrm{i}}$ and $\mathrm{q}_{\mathrm{i}}$, respectively. The increase in utility from consuming the product depends on each agent's unique preference factor denoted $\theta$. Preferences follow a uniform distribution over an interval bounded by a lower and upper value of $\theta$. The quality levels have this relationship: $\mathrm{q}_{\mathrm{L}}<\mathrm{q}_{\mathrm{H}}$. The symbol $\mathrm{q}_{\mathrm{H}}$ represents the quality level offered by the high-quality producer or the monopolist in the single seller case. In the duopoly market, the low quality producer offers $\mathrm{q}_{\mathrm{L}}$. The net benefit of consuming product variety $\mathrm{i}$ is given by the quantity $\theta \mathrm{q}_{\mathrm{i}}-\mathrm{P}_{\mathrm{i}}$.

Using the same basic concept, we propose the following profit function 
for the foreign investor in China:

where

$$
\mathrm{V}_{\mathrm{i}}(\kappa)=\mathrm{R}-\mathrm{T}_{\mathrm{i}}-\kappa \varepsilon_{\mathrm{i}}(\mathrm{i}=1, \ldots \mathrm{n})
$$

$\mathrm{R}$ : the level of return expected from an investment in a developing economy;

$\mathrm{T}_{\mathrm{i}}$ : the taxes imposed on the investor in city " $\mathrm{i}$ ";

$\kappa:$ the factor that determines the implicit costs to the foreign investor from the risk of the less-than-perfect business environment;

$\varepsilon_{\mathrm{i}}$ : a measure of the risk associated with business environment " $\mathrm{i}$ ".

Each investor has the same amount of capital to invest and makes one investment either in China or in a lesser developed economy with a higher level of risk. There is a continuum of such investors, and each has a unique value for $\kappa$, which identifies each investor. Each investment will produce a positive return, $\mathrm{R}$, in the form of a cash flow or increase in value for the investor. The Tier 1 city managers imposes a tax, $\mathrm{T}_{1}$, that it chooses to maximize net revenue from the foreign investors given the government's costs in improving the business environment by lowering $\varepsilon_{1}$ to a target level. That target level will be below $\varepsilon_{\mathrm{L}}$, which is the exogenous risk level of the lesser developed economies. ${ }^{31}$ Each foreign investor makes a decision concerning where to invest based upon the expected return, the tax rate, the quality of the business environment, and their ability to deal with the associated risk from a less-than-perfect business environment.

Effectively, each investor has the choice between an expected utility equal to $\mathrm{R}-\kappa \varepsilon_{\mathrm{L}}$ and paying $\mathrm{T}_{1}$ for an expected utility equal to $\mathrm{R}-\mathrm{T}_{1}-\kappa \varepsilon_{1}$, where $\varepsilon_{\mathrm{L}}>\varepsilon_{1}$. Investors characterized by $\kappa>\mathrm{T}_{1} /\left(\varepsilon_{\mathrm{L}}-\varepsilon_{1}\right)=\kappa^{*}$ will choose to pay $\mathrm{T}_{1}$ for only facing $\varepsilon_{1}$. In other words, investors with a higher value of $\kappa$, which means a lower ability to deal with the risk from a less-than-perfect business environment, are willing to pay the tax to be in an environment with a lower $\varepsilon_{\mathrm{i}}{ }^{32}$

As assumed in the ADT model and many other models of this type, $\kappa$ is uniformly distributed. The lower bound on $\kappa$ is zero, and there is an upper

\footnotetext{
${ }^{31}$ We can interpret $e_{L}$ as embodying the general level of risk in the world economy. It should decrease as the world economies grow more stable and integrated.

${ }^{32}$ We assume that $\mathrm{R}$ is the basic gross return earned in developing economies. It is the same for both Tier 1 and Tier 2 cities China and also the lesser-developed economies. The two returns do not necessarily have to be equal, but the net return earned in lesser developed economies outside of China must be greater than $R-T_{i}$ in China for $T_{i}>0$. Allowing that return earned outside of China to equal the gross return $\mathrm{R}$ in China simplifies the analysis, but allowing that return to be a fixed value greater than $\mathrm{R}$ will not change the nature of the equilibrium.
} 
bound, which we denote $\mathrm{K}$. The value of the density function over zero to $\mathrm{K}$ is the number of potential foreign investors divided by $\mathrm{K}$. Letting $\mathrm{N}$ represent the number of potential foreign investors and $\phi^{\prime}(\kappa)$ represent the density function, we can write $\phi^{\prime}(\kappa)=\mathrm{N} / \mathrm{K}$ when $0<\kappa<\mathrm{K}$, else $\phi^{\prime}(\kappa)=0$. At this point, we assume that $\mathrm{R}$ is sufficiently high so as to exceed both the tax rate and the expected losses from the less-than-perfect business environment. Future research will examine the implications of the possibility of $R<T_{i}+$ $\kappa \varepsilon_{\mathrm{i}}$.

The Tier 1 government incurs costs in lowering $\varepsilon_{\mathrm{i}}$ :

$$
\mathrm{C}\left(\cos t \mid \varepsilon_{1}\right)=\xi\left(\varepsilon_{\mathrm{L}}-\varepsilon_{1}\right)^{2}
$$

We assume that the costs are a function of how much the Tier 1 government lowers risks below that associated with lesser developed countries, $\left(\varepsilon_{\mathrm{L}}-\varepsilon_{1}\right)$, and that the principle of increasing costs applies. There is a scale factor, $\xi$, which could vary based on factors in the Chinese and world economies. The revenue function is:

$$
\pi_{1}=(\mathrm{N} / \mathrm{K})\left(\mathrm{K}-\kappa^{*}\right) \mathrm{T}_{1}-\xi\left(\varepsilon_{\mathrm{L}}-\varepsilon_{1}\right)^{2}
$$

The Tier 1 government chooses the lower level of level to offer, $\varepsilon_{1}$, and the tax rate to impose on foreign investors to maximize the city's net revenue. Substituting $\kappa^{*}$ into the net revenue function and optimizing with respect to the tax rate give this expression for the optimal tax rate: $\mathrm{T}_{1}{ }^{*}=\mathrm{K}\left(\varepsilon_{\mathrm{L}}-\varepsilon_{1}\right) / 2$. Using the assumed distribution of $\kappa$ gives the following expression:

$$
\kappa^{*}=\left[\mathrm{K}\left(\varepsilon_{\mathrm{L}}-\varepsilon_{1}\right) / 2\right] /\left(\varepsilon_{\mathrm{L}}-\varepsilon_{1}\right)=\mathrm{K} / 2
$$

This is a standard result where there is only one seller or service provider.

The first-order conditions ${ }^{33}$ provide the solution for the optimal $\varepsilon_{1}$ for the Tier 1 city managers to choose. The solution for the level of improvement is:

The optimal $\varepsilon_{1}$ is

$$
\varepsilon_{\mathrm{L}}-\varepsilon_{1}=0.125 \varepsilon_{\mathrm{L}} \mathrm{NK} / \xi
$$

$$
\varepsilon_{1}=\varepsilon_{\mathrm{L}}-0.125 \varepsilon_{\mathrm{L}} \mathrm{NK} / \xi
$$

Other things equal, a unit increase/decrease in the riskiness of lesser developed nations, given by $\varepsilon_{\mathrm{L}}$, will increase/decrease $\varepsilon_{1}$ by an equal amount. Other relationships are clear: $\mathrm{d} \varepsilon_{1} / \mathrm{dK}<0, \mathrm{~d} \varepsilon_{1} / \mathrm{dN}<0, \mathrm{~d} \varepsilon_{1} / \mathrm{d} \xi>0$. The Tier 1 city managers choose to differentiate themselves more from $\varepsilon_{\mathrm{L}}$ when either there are more investors, i.e., $\mathrm{N}$ increases, or there is a higher

\footnotetext{
${ }^{33}$ The first derivative is $\mathrm{d} \pi_{1} / \mathrm{d} \varepsilon_{1}=-\left(\mathrm{R}^{2} / 4\right)+2 \xi\left(\varepsilon_{\mathrm{L}}-\varepsilon_{1}\right) / \varepsilon_{\mathrm{L}}$. The second-order condition is satisfied: $\mathrm{d}^{2} \pi_{1} / \mathrm{d}\left(\varepsilon_{1}\right)^{2}=-2 \xi / \varepsilon_{\mathrm{L}}$.
} 
sensitivity to a less-than-perfect business environment as measured by an increase in $\mathrm{K}$. An increase in $\mathrm{N}$ increases the marginal revenue from a given increase in $T_{1}$, and the city managers will lower $\varepsilon_{1}$. The Tier 1 city managers find it profitable to accommodate an increase in the aversion of investors to business environment risk by distinguishing its environment more from $\varepsilon_{\mathrm{L}}$. Naturally, the Tier 1 city managers will decrease (increase) the target quality of the business environment, i.e., increase (decrease) $\varepsilon_{1}$, when the cost of doing so increases (decreases).

The optimal tax rate is $\mathrm{T}_{1}=0.0625 \varepsilon_{\mathrm{L}} \mathrm{NK}^{2} / \xi$, and $\mathrm{dT}_{1} / \mathrm{dK}>0, \mathrm{dT}_{1} / \mathrm{dN}>0$, $\mathrm{dT}_{1} / \mathrm{d} \xi<0$. Increases (decreases) in the number of investors and/or their aversion to the risks of a less-than-perfect business environment will allow the Tier 1 city managers to increase the tax rate. Interestingly enough, an increase in the scale factor $\xi$ for lowering $\varepsilon_{1}$ will decrease the tax rate, but this is because the city managers will have to allow $\varepsilon_{1}$ to increase, and foreign investors will want a decrease in the tax rate for the increase in $\varepsilon_{1}$.

The net revenue to the Tier 1 government is $\pi_{1}=0.015625 \varepsilon_{\mathrm{L}}(\mathrm{NK})^{2} / \xi$, and $\mathrm{d} \pi_{1} / \mathrm{dK}>0, \mathrm{~d} \pi_{1} / \mathrm{dN}>0, \mathrm{~d} \pi_{1} / \mathrm{d} \xi<0$. As we would expect, net revenue increases when the number of investors increase or the scale parameter in the cost function decreases. Interestingly enough, net revenue increases when foreign investors have a higher level of aversion to investing in a lessthan-perfect business environment.

These results hold when $\kappa$ follows a distribution other than the uniform distribution. A cumulative distribution function, denoted $\phi(\kappa)$, can help create a more general expression for net revenue:

$$
\pi_{1}=\mathrm{NR}_{1}\left\{1-\phi\left[\mathrm{R}_{1} /\left(\varepsilon_{\mathrm{L}}-\varepsilon_{1}\right)\right]\right\}-\xi\left(\varepsilon_{\mathrm{L}}-\varepsilon_{1}\right)^{2}
$$

The optimal tax rate is $\mathrm{T}_{1}{ }^{*}=\left[1-\phi\left(\kappa^{*}\right)\right] /\left[\left(\varepsilon_{\mathrm{L}^{-}} \varepsilon_{1}\right)-\phi^{\prime}\left(\kappa^{*}\right)\right]$, which then gives the expression: $\kappa^{*}=\left[1-\phi\left(\kappa^{*}\right)\right] / \phi^{\prime}\left(\kappa^{*}\right)$. The value of $\kappa^{*}$ is a constant nominal value for many distributions. Unique solutions exist for $\kappa^{*}$ and the second order conditions are satisfied when $\phi(\kappa)$ represents a uniform, normal or exponential distribution ${ }^{34}$.

The section has introduced the model and developed results when only a Tier 1 city exists and competes against an exogenous, lesser developed economy for foreign investment. For the most part, the results are straightforward and conform to intuition. The process has allowed for the introduction of parameters and assumptions of the model in a relatively simple case. The next section investigates the results when a Tier 2 city in China attempts to attract foreign investors by offering a lower tax rate but

\footnotetext{
${ }^{34}$ There are distributions for which $\kappa *$ is not unique. One example is $\phi(\kappa)=1-K / \kappa ; \kappa:[K+\infty)$, where $\mathrm{K}$ is a positive constant.
} 
also a lower quality business environment.

\section{COMPETITION BETwEen TIER 1 AND TIER 2 CITIES}

To describe the interaction of the Tier 1 and Tier 2 cities, we use the widely used assumption that the city managers engage in a quality then price two-stage game. In this case, the quality is the level of risk associated with the city's business environment, and the price is the tax rate. Representative works using this assumption include Tirole $(1988)^{35}$, Jehiel $(1992)^{36}$ and Xavier (1996) ${ }^{37}$. The model developed here has a stable equilibrium that defines the proportional number of investors in each city tier, the respective tax rates, the values $\varepsilon_{1}$ and $\varepsilon_{2}$, and net revenues to the cities in terms of the external parameters defined in the previous section.

In the first stage of the game, the city managers of the two city tiers recognize how their choices of $\varepsilon_{\mathrm{i}}$ determine the relative number of foreign investors who will invest in their respective cities. They also recognize the benefits of distinguishing themselves so that $\varepsilon_{2}>\varepsilon_{1}$ and $T_{2}<T_{1}$. The subscripts refer to the tier of each city. Recalling Equation (2), the condition that leads a foreign investor to choose the Tier 1 city over the Tier 2 city is $-T_{1}-\kappa \varepsilon_{1}>-T_{2}-\kappa \varepsilon_{2}$. The preference factors for the marginal investors are:

$$
\begin{gathered}
\kappa_{1}{ }^{*}=\left(\mathrm{T}_{1}-\mathrm{T}_{2}\right) /\left(\varepsilon_{2}-\varepsilon_{1}\right) \\
\kappa_{2}{ }^{*}=\mathrm{T}_{2} /\left(\varepsilon_{\mathrm{L}}-\varepsilon_{2}\right)
\end{gathered}
$$

The term $(\mathrm{N} / \mathrm{K})\left(\mathrm{K}-\kappa_{1}{ }^{*}\right)$ indicates the number of investors who choose to invest in Tier 1 . The corresponding measure for Tier 2 is $(\mathrm{N} / \mathrm{K})\left(\kappa_{1}{ }^{*}-\kappa_{2}{ }^{*}\right)$. Solving for each $\mathrm{T}_{\mathrm{i}}^{*}$ as before yields,

$$
\begin{aligned}
& \mathrm{T}_{1}^{*}=2 \mathrm{~K}\left(\varepsilon_{2}-\varepsilon_{1}\right)\left(\varepsilon_{\mathrm{L}}-\varepsilon_{1}\right) /\left(3 \varepsilon_{\mathrm{L}}+\varepsilon_{2}-4 \varepsilon_{1}\right) \\
& \mathrm{T}_{2}{ }^{*}=\mathrm{K}\left(\varepsilon_{2}-\varepsilon_{1}\right)\left(\varepsilon_{\mathrm{L}}-\varepsilon_{2}\right) /\left(3 \varepsilon_{\mathrm{L}}+\varepsilon_{2}-4 \varepsilon_{1}\right)
\end{aligned}
$$

For ease of notation we write $\mathrm{T}_{1}{ }^{*}=2 \mathrm{~K} \delta_{2,1} \delta_{\mathrm{L}, 1} / \omega$ and $\mathrm{T}_{2}{ }^{*}=\mathrm{K} \delta_{2,1} \delta_{\mathrm{L}, 2} / \omega$. The implied transformations are $\delta_{\mathrm{L}, 1}=\varepsilon_{\mathrm{L}}-\varepsilon_{1}, \quad \delta_{\mathrm{L}, 2}=\varepsilon_{\mathrm{L}}-\varepsilon_{2}, \quad \delta_{2,1}=\varepsilon_{2}-\varepsilon_{1}$, $\omega=3 \varepsilon_{\mathrm{L}}+\varepsilon_{2}-4 \varepsilon_{1}$.

The net revenue functions in the first stage of the game are:

$$
\begin{gathered}
\pi_{1}=4 \mathrm{NK} \delta_{2,1} \delta_{\mathrm{L}, 1}{ }^{2} / \omega^{2}-\xi\left(\delta_{\mathrm{L}, 1}\right)^{2} \\
\pi_{2}=\mathrm{NKK} \delta_{\mathrm{L}, 2} \delta_{2,1} \delta_{\mathrm{L}, 1} / \omega^{2}-\xi\left(\delta_{\mathrm{L}, 2}\right)^{2}
\end{gathered}
$$

\footnotetext{
35 Tirole, J., The Theory of Industrial Organization (Cambridge, MiT Press 1988).

${ }^{36}$ Jehiel, P., Product Differentiation and Price Collusion, 10 InTERNATIONAL JourNAL OF INDUSTRIAL ORgANIZATION 633-641 (1992).

${ }^{37}$ Xavier, W., Quality Choice in Models of Vertical Differentiation, 44 THE JouRnAL OF INDUSTRIAL ECONOMICS 345-353 (1996).
} 
The first order conditions for the Tier 1 and Tier 2 cities respectively are ${ }^{38,}$

$$
\begin{gathered}
\xi=2 \mathrm{NK} \varepsilon_{\mathrm{L}}\left(2 \delta_{\mathrm{L}, 2}{ }^{2}-3 \delta_{\mathrm{L}, 1} \delta_{\mathrm{L}, 2}-4 \delta_{\mathrm{L}, 1}{ }^{2}\right) /\left(\delta_{\mathrm{L}, 1} \omega^{3}\right) \\
\xi=\mathrm{NK} \varepsilon_{\mathrm{L}} \delta_{\mathrm{L}, 1}\left(4 \delta_{\mathrm{L}, 1}-7 \delta_{\mathrm{L}, 2}\right) /\left(2 \delta_{\mathrm{L}, 2} \omega^{3}\right)
\end{gathered}
$$

Equating the two expressions for $\xi$ gives a third degree polynomial in a variable defined as $\delta_{\mathrm{L}, 1} / \delta_{\mathrm{L}, 2}$. Only a single real-root exists: $\delta_{\mathrm{L}, 1} / \delta_{\mathrm{L}, 2}=5.25123$. Entering this value into the equations above yields solutions for the degree to which each city improves the business environment above that of lesser developed economies:

$$
\begin{array}{r}
\delta_{\mathrm{L}, 1}=\varepsilon_{\mathrm{L}}-\varepsilon_{1}=0.12665 \mathrm{NK} \varepsilon_{\mathrm{L}} / \xi \\
\delta_{\mathrm{L}, 2}=\varepsilon_{\mathrm{L}}-\varepsilon_{2}=0.02412 \mathrm{NK} \varepsilon_{\mathrm{L}} / \xi
\end{array}
$$

These expressions define several interesting relationships. Using the term $\varepsilon_{\mathrm{L}} \mathrm{NK} / \xi$ as a unit of measure, for example, Tier 2 city managers improve $\varepsilon_{\mathrm{L}}$ to $\varepsilon_{2}$, but that distance is less than one fifth of the distance of $\varepsilon_{\mathrm{L}}-\varepsilon_{1}$.

The tax rates are $\mathrm{T}_{1}=0.05383 \mathrm{NK}^{2} \varepsilon_{\mathrm{L}} / \xi$ and $\mathrm{T}_{2}=0.00513 \mathrm{NK}^{2} \varepsilon_{\mathrm{L}} / \xi$. Net revenues per period are $\pi_{1}=0.0122193(\mathrm{NK})^{2} \varepsilon_{\mathrm{L}} / \xi$ and $\pi_{2}=0.0005075(\mathrm{NK})^{2} \varepsilon_{\mathrm{L}} / \xi$. We should note that the Tier 1 city's net revenue is higher, but this depends upon our assumption that $\mathrm{R}>\mathrm{T}_{1}+\kappa \varepsilon_{1}$ for all the investors, i.e., $\mathrm{T}_{1}$ and $\varepsilon_{1}$ are not so high as to eliminate some possible investors with high values of $\kappa$.

The competition between the Tier 1 city and Tier 2 city forces tax rates on foreign investment to decline. The Tier 1 tax rate, $\mathrm{T}_{1}$, in the two-city model is about $14 \%$ lower than $\mathrm{T}_{1}$ in the one-city model. The corresponding $\varepsilon_{1}$ declines by about $1 \%$, which means the existence of the Tier 2 choice for investors leads to the Tier 1 city managers lowering the quality of the business environment slightly, but they lower taxes much more in percentage terms. These adjustments increase the proportion of foreign investors who choose the Tier 1 city from $50 \%$ in the one-city case to $52.5 \%$. The Tier 2 city attracts $26.25 \%$ of all potential foreign investors. The remaining $21.25 \%$ of the investors choose to invest in lesser developed economies outside of China. By allowing the two-tier competition, the total foreign investment in China increases by $57.5 \%=[(52.5 \%+26.25 \%) / 50 \%-1]$ when compared with the single tier economy. These results hold as long as both Tier 1 and Tier 2 cities remain in the market and they both have the same value for $\xi$.

\footnotetext{
${ }^{38}$ The first-order conditions yield reaction functions in the plane defined by $\varepsilon_{1}$ and $\varepsilon_{2}$. The first order conditions give: $\varepsilon_{2}=5.25123 \varepsilon_{1}-4.25123 \varepsilon_{\mathrm{L}}$; therefore when an equilibrium combination of $\varepsilon_{2}$ and $\varepsilon_{1}$ exists, it is unique. The second-order conditions are satisfied: $\mathrm{d}^{2} \pi_{1} / \mathrm{d} \varepsilon_{1}{ }^{2}=-8 \mathrm{NK}\left(\delta_{\mathrm{L}, 2}+5 \delta_{\mathrm{L}, 1}\right) \delta_{\mathrm{L}, 2}{ }^{2} / \omega^{4}<0$; $\mathrm{d}^{2} \pi_{2} / \mathrm{d} \varepsilon_{2}{ }^{2}=-2 \mathrm{NK}\left(7 \delta_{\mathrm{L}, 2}+8 \delta_{1, \mathrm{~L}}\right) \delta_{1, \mathrm{~L}}{ }^{2} / \omega^{4}<0$.
} 
This section has demonstrated how this equilibrium can exist in the competition for foreign investors between the Tier 1 and Tier 2 cities in China. The model builds upon that proposed by ADT by offering the agents choosing between the two qualities a third, exogenous choice. In our model, that the third choice is to invest outside of China in a lesser developed country. Under these conditions, a unique set of tax rates, net revenues, number of investors and qualities of business environments results. The next section examines how changes in exogenous parameters affect the resulting values in that equilibrium.

\section{The EFFeCt OF EXogenous SHIFTS IN THE TIER 1 AND TIER 2 CiTY MODEL}

This section examines how changes in exogenous parameters affect the equilibrium derived in the previous section. Comparative statics yield interesting results with respect to the impact on the equilibrium qualities of business environments, tax rates and net revenues in response to changes in $\varepsilon_{\mathrm{L}}, \xi, \mathrm{N}$ and $\mathrm{K}$. Respectively, these parameters relate to an exogenous level of risk, a scale parameter for cost to the cities for improving the business environment, the number of potential foreign investors, and the aversion investors have to the risks of a less-than-perfect business environment.

The results in the previous sections yield the following expressions: $\varepsilon_{1}=\varepsilon_{\mathrm{L}}-0.12665 \mathrm{NK} \varepsilon_{\mathrm{L}} / \xi$ and $\varepsilon_{2}=\varepsilon_{\mathrm{L}}-0.02412 \mathrm{NK} \varepsilon_{\mathrm{L}} / \xi$. The distance between the two levels is $\varepsilon_{1}-\varepsilon_{2}=0.10253 \mathrm{NK} \varepsilon_{\mathrm{L}} / \xi$. Thus, when $\varepsilon_{\mathrm{L}}$ changes, not only quality levels change in the same direction, but also the distance between them changes. An increase (decrease) at the general level of risk in lesser developed countries, as represented by $\varepsilon_{\mathrm{L}}$, would increase (decrease) the risk of the environment in both Tier 1 and Tier 2 cities, and $\varepsilon_{1}$ and $\varepsilon_{2}$ would diverge (converge). Exogenous political and economic conditions in the world would determine the value of $\varepsilon_{\mathrm{L}}$.

An increase in $\mathrm{K}$ implies that the foreign investors are more averse to the associated risks, which could mean that they have a lower level of expertise for dealing with this type of risk and/or that they expect to incur more costs from such risks. Tier 1's quality level of business environment is more sensitive to changes in $\mathrm{K}$ :

$$
\left|\mathrm{d} \varepsilon_{1} / \mathrm{dK}\right|=\left|-0.12665 \mathrm{~N} \varepsilon_{\mathrm{L}} / \xi\right|>\left|\mathrm{d} \varepsilon_{2}{ }^{2} / \mathrm{dK}\right|=\left|-0.02414 \mathrm{~N} \varepsilon_{\mathrm{L}} / \xi\right|
$$

The equilibrium conditions imply that Tier 1 and Tier 2 city managers will accommodate an increase in $\mathrm{K}$ by lowering $\varepsilon_{\mathrm{i}}$ in their respective cities. The decline in $\varepsilon_{1}$ will be much larger in the Tier 1 city, which indicates that 
the qualities of the Tier 1 and Tier 2 business environments will diverge. ${ }^{39}$

Changes in $\mathrm{K}$ will affect tax rates and net revenues for both cities in the same direction but with different magnitudes: $\mathrm{dT}_{1} / \mathrm{dK}=0.10766 \mathrm{NK} \varepsilon_{\mathrm{L}} / \xi$, $\mathrm{dT}_{2} / \mathrm{dK}=0.01026 \mathrm{NK} \varepsilon_{\mathrm{L}} / \xi, \quad \mathrm{d} \pi_{1} / \mathrm{dK}=0.02443864 \mathrm{KN}^{2} \varepsilon_{\mathrm{L}} / \xi, \quad$ and $\mathrm{d} \pi_{2} / \mathrm{dK}=0.001015 \mathrm{KN}^{2} \varepsilon_{\mathrm{L}} / \xi$. An increase in $\mathrm{K}$ will increase the tax rates and revenues and also lead to both the difference between the tax rates and the difference between the net revenues increasing. In summary, an increase (decrease) in $\mathrm{K}$ decreases (increases) both $\varepsilon_{1}$ and $\varepsilon_{2}$, and the values diverge (converge), taxes increase (decrease) and diverge (converge) and net revenues increase (decrease) and diverge (converge). This means that if there is a trend for foreign investors to become more willing and able to deal with the risks represented by $\varepsilon_{\mathrm{i}}$, as represented by a decline in $\mathrm{K}$, then the Tier 1 and Tier 2 cities will become more similar, but the risk levels will increase.

Since the term (NK) appears in the expressions for tax rates, net revenues, and $\varepsilon_{\mathrm{i}}$, it should be obvious that an increase in the number of potential foreign investors will affect the equilibrium in basically the same way as an increase in $\mathrm{K}$. With a larger number of potential investors, the Tier 1 and Tier 2 city managers find that they can increase profits by decreasing their respective $\varepsilon_{\mathrm{i}} \mathrm{s}$ and increasing the tax rates. There is the interesting possibility here that a simultaneous trend of an increasing number of investors, i.e., an increasing $\mathrm{N}$, and an increasing level of sophistication, i.e., a decreasing $\mathrm{K}$, could have effects that offset each other to keep the choice variables of each city relatively constant.

Each city incurs costs for lowering $\varepsilon_{\mathrm{i}}$, and a scale factor affects the choice levels:

$$
\varepsilon_{1} / \mathrm{d} \xi=0.12665 \mathrm{NK} \varepsilon_{\mathrm{L}} / \xi^{2}>\mathrm{d} \varepsilon_{2} / \mathrm{d} \xi=0.02412 \mathrm{NK} \varepsilon_{\mathrm{L}} / \xi^{2}
$$

The risk levels go up from an increase in $\xi$, but $\mathrm{d}\left(\varepsilon_{2^{-}} \varepsilon_{1}\right) / \mathrm{d} \xi=$ $-0.10253 \mathrm{NK} / \xi^{2}$. In summary, an increase (decrease) in $\xi$ will increase (decrease) both $\varepsilon_{1}$ and $\varepsilon_{2}$, and the levels converge (diverge), i.e., the quantity $\varepsilon_{2}-\varepsilon_{1}$ decreases (increases). An increase (decrease) in $\xi$ will decrease (increase) net revenues and the absolute difference between the net revenues will converge (diverge). An increase (decrease) in $\xi$ will decrease (increase) the tax rates as the city managers of the cities increase (decrease) the $\varepsilon_{\mathrm{i}} \mathrm{s}$, and

\footnotetext{
${ }^{39}$ One reason that the choice variables for the Tier 2 city are less responsive is that $\varepsilon_{\mathrm{L}}$ is exogenous. If $\mathrm{K}$ decreases, officials of both city governments will allow $\varepsilon_{1}$ and $\varepsilon_{2}$ to increase, but the officials of the Tier 2 city cannot allow $\varepsilon_{2}$ to increase too much because $\varepsilon_{\mathrm{L}}$ does not change. Future research can explore the implications of allowing $\varepsilon_{\mathrm{L}}$ to be endogenous, i.e., allowing the external economies to react to the decisions of the Tier 1 and Tier 2 cities.
} 
the tax rates will converge (diverge).

These results can help analysts answer some interesting questions. If the ability of the governments to improve the business environments improves, for example, it is interesting to note that the business environments will become less similar. If the ability of investors for dealing with the risks improves, the quality of the business environments may deteriorate and converge. The concluding section discusses this version of the model and the implications of the findings given potential trends in the world.

\section{Central Control of Qualities OfFered}

In China, the central government can exercise a high level of control over the activities of the various regions. In this section, we demonstrate how the cities might benefit from mandates from the central government concerning taxes and targeted business environment quality levels. As usual, there will be a trade-off in that the results from the mandated choice variables will increase net tax revenue but will lower the amount of investment.

As indicated in the previous section, the introduction of the indirect competition by the addition of a lower tier city to the analysis induces the Tier 1 city to lower its quality level and lower its price, which lowers its net tax revenue. The quality level in the single city tier model is $\varepsilon_{\mathrm{L}}-0.125 \varepsilon_{\mathrm{L}} \mathrm{NK} / \xi$, and the quality level offered by the Tier 1 city in the twocity model is $\varepsilon_{\mathrm{L}}-0.12665 \mathrm{NK} \varepsilon_{\mathrm{L}} / \xi$. The corresponding net revenues are $0.015625 \varepsilon_{\mathrm{L}}(\mathrm{NK})^{2} / \xi$, in the single tier case, and $0.0122193(\mathrm{NK})^{2} \varepsilon_{\mathrm{L}} / \xi$ in the two-tier case. If the Tier 1 city maintains its original quality level by mandate of the central government, then the Tier 2 city managers would consider $\varepsilon_{1}=\varepsilon_{\mathrm{L}}-0.125 \varepsilon_{\mathrm{L}} \mathrm{NK} / \xi$ an exogenous level like $\varepsilon_{\mathrm{L}}$, and the target population of potential investors would be those with preferences below $\mathrm{K} / 2$. The optimal quality level for the Tier 2 city is then $\varepsilon_{\mathrm{L}}-0.025 \mathrm{NK} \varepsilon_{\mathrm{L}} / \xi$. The corresponding net revenue level is $0.0009766(\mathrm{NK})^{2} \varepsilon_{\mathrm{L}} / \xi$, which is almost double that in the competitive case. The potential drawback is that there will be less total foreign investment because of the higher tax rates in both cities. In the competitive two-tier city model, $78.75 \%$ of all potential investors invest in the two city tiers. In the model where the central government mandates the net revenue maximizing quality levels to the two tiers, only $75 \%$ of all investors invest. Thus, the government will have to determine if the increase in tax revenue is worth the decline in investment. The increase in tax revenue from the central control of tiers is 
$30.45 \%=[(0.015625+0.0009766) /(0.0122193+0.0005075)-1]$, and the decline in foreign investment is $4.67 \%=|(75 \% / 78.75 \%)-1|$.

\section{CONCLUSION}

This paper demonstrates a methodology for analyzing how the higher tier and lower tier cities in China can coexist with different quality levels in terms of their business environments and tax rates. Established research supports the proposition that equilibrium is possible in a competition for foreign investment where the cities differentiate themselves with the indicated choice variables. Our model demonstrates how exogenous variables determine the qualities of the business environments, the tax rates, and net revenues in the cities in different tiers, and it gives insights into how the characteristics of the cities might change in absolute terms and relative to each other in reaction to changes in exogenous variables.

Given global trends, the model can help analysts answer important questions concerning the trends in the characteristics of the different tiers of cities in China. The general question is how will the cities change over time in both absolute and relative terms. More specifically, what domestic and world trends will lead to the higher tier and lower tier cities becoming more or less similar in terms of their business environments. What trends will raise and lower the qualities?

If the number of potential investors increases, for example, the model predicts that the business environments will improve. This is a favorable result from a trend that is likely to continue. It is important to note that changes in the aversion to the risks of a less-than-perfect business environment have similar effects. This means that if the investors become more sophisticated and adept in dealing with the risks, the business environments in China will deteriorate and become more similar. On the other hand, if less sophisticated investors begin to enter the market as the numbers of investors increase, the environments will improve.

The model also gives insights concerning how China might react to changes in the competition for foreign investment. The quality of the business environment in lesser developed economies may improve over time. The model predicts that the Chinese cities in the different tiers will have to improve their environments, and the quality levels in China will converge.

Other developing countries can use this model to determine the potential effects of creating tiers for foreign investors in their respective economies. A comparison between the single-tier and the two-tier city 
models in this paper shows that the total revenues to the local governments will decline with the introduction of a second tier. However, the number of total investors and the total investment will increase by more than $50 \%$. Thus, even though net revenue from the foreign investors to the governments will decline, the significant increase in investment is likely to create other activities that create additional wealth and tax revenues. Furthermore, we demonstrate that attempts to control the levels of business environments by the central government to increase net revenues may increase net tax revenues, but it will lead to lower total investment. The decline in the amount invested could have long-run negative implications for the economy that are far greater than the benefits of higher net revenues in the current period.

These results provide a foundation for a great deal of empirical work that can provide insights into the development of the Chinese economy and other economies around the world with respect to their attempts to improve their respective business environments and attract foreign investment. The results provide a foundation for additional theoretical work where future research can address the implications of relaxing assumptions, e.g., assumptions concerning the distribution of the tastes of potential investors and the expected return on the investments. Although game theory models can become very complex, continued work in this field will allow researchers and practitioners to better understand the evolution of developing economies and the changes in their business environments. 